\title{
Study the Effect of Early Administration of Amino Acid Infusion on Preterm Neonate
}

\section{Mohamed S El Frargy ${ }^{1 *}$, Abd El- Rahman M El- Mashad ${ }^{1}$ and Amany M Abo El-Enin ${ }^{2}$}

${ }^{1}$ Department of Pediatrics and Clinical Pathology, Faculty of Medicine, Tanta University, Egypt

${ }^{2}$ Department of Clinical Pathology, Faculty of Medicine, Tanta University, Egypt

\begin{abstract}
Background: Neonatal hyperglycemia is a common problem in preterm neonates.

Patient and methods: A prospective cohort study was conducted on 200 neonates in neonatal intensive care unit (NICU) at Tanta University Hospital from June 2012 to June 2014.

Group I: Included 100 preterm neonates that were given intravenous amino acids starting from the 3rd day of birth and lasting for 5 consecutive days and tested for serum albumin, total proteins and random blood glucose levels.

Group II: Included 100 preterm neonates of matched gestational age as a control group. Results There was no statistically significant difference between case and control in the 1st three days of life before the AAs infusion as both groups were liable to hyperglycemia while there was statistically significant decrease in the number of hyperglycemic and hypoglycemic patient with euglycemia starting from the fourth day of life after the amino acids infusion. There was no significant difference in the 1st reading of TSP level on the 3rd day of life between cases and control while there was significant difference in the 2 nd reading on the 8 th day of life.
\end{abstract}

Conclusion: Amino acids infusion in preterm neonates cause improvement of glycemic variability and cause stimulation of protein synthesis.

Keywords: Neonate; Preterm; Aminoacid

\section{Introduction}

Preterm birth is defined by WHO as all births before 37 completed weeks of gestation. Preterm birth can be further sub-divided based on gestational age (GA): extremely preterm ( $<28$ weeks), very preterm $(28-<32$ weeks $)$ and moderate preterm $(32-<37$ completed weeks of gestation). Moderate preterm birth may be further split to focus on late preterm (near term) birth (34-<37 completed weeks) [1].

Glycemic variability, resulting in hyper- or hypoglycemia, is a common complication of prematurity and stress in neonatal intensive care units (NICUs) $[2,3]$.

Neonatal hyperglycemia is a common problem in preterm or sick neonates in the first few weeks of life which is associated with higher mortality and morbidity rates and negative prognosis in the long term $[4,5]$.

There is currently no best practice method or target for glycemic control in preterm babies who is associated with reduced insulin sensitivity (IS) and blood glucose is often controlled by varying nutritional input which may restrict infant growth and cause adverse neurodevelopmental outcomes [6,7].

The normal serum albumin concentrations in preterm and term newborns have marked variations. Mean albumin concentrations at birth increase from $1.9 \mathrm{~g} / \mathrm{dL}$ at 25 weeks' gestation to $3.1 \mathrm{~g} / \mathrm{dL}$ at 42 weeks' gestation. Postnatal, serum albumin concentrations in preterm infants rise at a similar rate as the intrauterine rate up to 8 weeks of age [8].

Nutritional care of the prematurely born low birth weight infant, continues to be the major challenge for the clinical neonatologist. Suboptimal nutrition is associated with adverse outcomes which include increased susceptibility to infections, greater need for mechanical ventilation and development of chronic lung disease [9].
Early postnatal provision of IV amino acids to preterm infants produces greater rates of protein synthesis and net protein balance [10]

\section{Patients and Methods}

This study included 200 preterm neonates ( 84 males \& 116 females) who were admitted at NICU of Tanta university, between June 2012 and June 2014.

This is a prospective cohort study in which the neonates were divided into 2 groups:

Group I: Included 100 preterm neonates ranging between 30 and 34 weeks of gestation that were given intravenous amino acids starting from the 3rd day of birth and lasting for 5 consecutive days and tested for serum albumin, total proteins and insulin levels on the 3rd day and the 8th day with daily follow up of random blood glucose levels from the 1 st to the 8 th day of life.

Group II: Included 100 preterm neonates of matched gestational age as a control group with measurement of serum albumin, total proteins and insulin levels on the 3rd day and the 8th day with daily follow up of random blood glucose levels from the 1st to the 8th day of life.

*Corresponding author: Mohamed S El Frargy, Department of Pediatrics and Clinical Pathology, Faculty of Medicine, Tanta University, Egypt, Tel: +20 01005171750; E-mail: farargy2009@hotmail.com

Received December 27, 2015; Accepted January 21, 2016; Published January 28, 2016

Citation: El Frargy MS, El- Mashad ARM, El-Enin AMA (2016) Study the Effect of Early Administration of Amino Acid Infusion on Preterm Neonate. J Neonatal Biol 5 209. doi:10.4172/2167-0897.1000209

Copyright: ( 2016 El Frargy MS, et al. This is an open-access article distributed under the terms of the Creative Commons Attribution License, which permits unrestricted use, distribution, and reproduction in any medium, provided the original author and source are credited. 
A written informed consent was taken from the parents of the two groups.

The aim of the study is to evaluate the value of intravenous amino acids infusion on the reduction of neonatal hyperglycemia and their effect on protein synthesis especially insulin and albumin.

\section{Inclusion criteria}

Preterm neonates from 30 to 34 weeks of gestation with or without respiratory distress due to causes other than sepsis.

\section{Exclusion criteria}

1-Preterm neonates with congenital anomalies or sepsis

2-SGA

3-IDM

4- Preterm neonates with HIE 5-Preterm neonates with inborn errors of metabolism.

All neonates included in the study was subjected to the following:

1. Complete history taking.

2. Full clinical examination: including physical measurement, vital signs and neurological examination.

3. Laboratory investigations:

a) $\mathrm{CBC}, \mathrm{CRP}$.

b) Random blood glucose level.

c) Total serum proteins and albumin levels.

d) Serum insulin level.

Type of amino acid used in the study

Aminoven infant $10 \%$ product of Fresenius Kabi

\section{Composition}

Each $1000 \mathrm{ml}$ contain L-leucine $13 \mathrm{~g}$, L-isoleucine $8 \mathrm{~g}$, L-lysine acetate $12 \mathrm{~g}$ = L- lysine acetate8.51g, L-methionine $3.12 \mathrm{~g}, \mathrm{~L}$ phenylalanine $3.75 \mathrm{~g}$, L- therionine $4.4 \mathrm{~g}$, L-tryptophan $2.01 \mathrm{~g}$, L-valine $9 \mathrm{~g}$, Arginine $7.5 \mathrm{~g}$, -L histidine $4.76 \mathrm{~g}$, Glycine $4.15 \mathrm{~g}$, L-taurine $0.4 \mathrm{~g}$, L-serine $7.76 \mathrm{~g}$, L-alanine $9.3 \mathrm{~g}$, L-proline $9.71 \mathrm{~g}, \mathrm{~N}$-acetyl-L tyrosine $5.176 \mathrm{~g}=\mathrm{L}$-tyrosine $4.2 \mathrm{~g}, \mathrm{~N}$-acetyl L-cysteine $0.7 \mathrm{~g}=\mathrm{L}$-cysteine $0.52 \mathrm{~g}$, L-malic acid $2.62 \mathrm{~g}$.

Theoretical osmolarity: $885 \mathrm{mosm} / 1$

\section{Dose used in this study}

$1 \mathrm{~g} / \mathrm{kg} /$ day started from the $3 \mathrm{rd}$ day of life increased to $2 \mathrm{~g} / \mathrm{kg} /$ day on the 2 nd day of AAs infusion and to $3 \mathrm{~g} / \mathrm{kg} /$ day on the $3 \mathrm{rd}$ day of the infusion and continue on the same dose till the 8 th day of life.

\section{Sampling}

$5 \mathrm{ml}$ of the patient blood was taken divided into:

1-One milliliter of patients' blood was taken on ethylene diamine tetra-acetic acid (EDTA) tube and assayed immediately for complete blood picture by automated way.

2-Two milliliters of patients' blood was taken on serum separator tube (SST) and allowed to clot before centrifugation for 15 minutes. Serum was separated and assayed immediately for random blood sugar, total serum proteins, albumin and CRP.
3-Two milliliters of patients' blood were taken on serum separator tube (SST) and allowed to clot before centrifugation for 15 minutes. Serum was separated and assayed immediately for insulin level.

Statistical analysis was performed by using SPSS for Windows, version 20. Data were expressed as range and mean \pm standard deviation (SD). Differences between groups in continuous variables were tested for significance with independent $t$-test while Chi-square test (X2) used to compare categorical variables. For all statistical tests done, $\mathrm{p}$ value $<0.05$ was considered significant.

\section{Results}

200 preterm neonates were included in this study divided into 2 groups

Group I: Included 100 preterm neonates 40 males (40\%) and 60 females (60\%) who were given intravenous amino acids starting from the 3rd day of birth and lasting for 5 consecutive days.

Group II: Included 100 preterm neonates of matched gestational age as a control group that include 44 males (44\%) and 56 female (56\%).

The neonates of the two groups had gestational ages ranging from 30 to 34 gestational weeks as shown.

From the above table, there was no statistical difference considering sex and gestational age. Between case and control groups (Table 1).

The above table show there is no statistically significant difference between the two studied groups as regard the birth weight (Table 2).

As regard the CRP, no evidence of sepsis and no statistically significant difference between the case group and the control group (Table 3).

The above table shows that there was no statistically significant difference between the case group and the control group in the 1st three days of life before the AAs infusion as both groups were liable to hyperglycemia (Table 4).

There was statistically significant decrease in the number of hyperglycemic and hypoglycemic patient with euglycemia starting from the fourth day of life after the amino acids infusion.

There was no significant difference in the 1 st reading of TSP level on the 3rd day of life between cases and control while there was significant difference in the 2 nd reading on the 8 th day of life (Table 5).

There was no significant difference in the 1 st reading on the 3 rd day of life between cases and control while there was significant difference in the 2 nd reading of albumin level on the 8 th day of life.

The above table show that there was statistically significant decrease

\begin{tabular}{|c|c|c|c|c|c|c|}
\hline & Cases $(n=100)$ & & $\begin{array}{c}\text { Control }(n= \\
100)\end{array}$ & & \multirow{2}{*}{ Test of sig. } & \multirow[t]{2}{*}{$\mathbf{P}$} \\
\hline & No. & $\%$ & No. & $\%$ & & \\
\hline \multicolumn{7}{|l|}{ Sex } \\
\hline Male & 40 & 40 & 44 & 44 & \multirow{2}{*}{$x^{2}=0.08$} & \multirow{2}{*}{0.5} \\
\hline Female & 60 & 60 & 56 & 56 & & \\
\hline \multicolumn{7}{|l|}{$\begin{array}{c}\text { Gestational } \\
\text { age }\end{array}$} \\
\hline Range & \multicolumn{2}{|l|}{$30.0-34.0$} & \multicolumn{2}{|c|}{$30.0-34.0$} & \multirow{2}{*}{$t=1.644$} & \multirow{2}{*}{0.107} \\
\hline Mean \pm SD & \multicolumn{2}{|l|}{$31.96 \pm 1.43$} & \multicolumn{2}{|c|}{$32.28 \pm 1.40$} & & \\
\hline
\end{tabular}

Table 1: Comparison between the two studied groups according to demographic data. 


\begin{tabular}{|c|c|c|}
\hline Wt on admission $\mathbf{( K g )}$ & Cases $\mathbf{( n = 1 0 0 )}$ & Control $(\mathbf{n}=\mathbf{1 0 0})$ \\
\hline Range & $1.1-2.2$ & $1.3-2.2$ \\
\hline Mean \pm SD & $1.61 \pm 0.29$ & $1.76 \pm 0.27$ \\
\hline T. test & 3.979 & \\
\hline P. value & 0.052 & \\
\hline
\end{tabular}

Table 2: Comparison between the two studied groups as regard birth weight.

\begin{tabular}{|c|c|c|c|c|c|}
\hline & & Cases $(\mathbf{n}=100)$ & Control $(\mathbf{n}=100)$ & $\mathbf{t}$ & $\mathbf{p}$ \\
\hline CRP & Range & $0.0-6.0$ & $0.0-6.0$ & $Z=0.590$ & 0.556 \\
\hline & Mean \pm SD. & $0.48 \pm 1.66$ & $0.24 \pm 1.20$ & & \\
\hline
\end{tabular}

*: Statistically significant at $p \leq 0.05$

Table 3: Comparison between the two studied groups regarding CRP.

\begin{tabular}{|c|c|c|c|c|c|c|}
\hline & $\begin{array}{c}\text { Cases } \\
(n=100)\end{array}$ & & $\begin{array}{l}\text { Control } \\
(n=100)\end{array}$ & & $x^{2}$ & $\mathbf{P}$ \\
\hline & No. & $\%$ & No. & $\%$ & & \\
\hline \multicolumn{7}{|l|}{ RBS 1} \\
\hline Hypoglycemia & 0 & 0 & 4 & 4 & \multirow{3}{*}{1.213} & \multirow{3}{*}{0.547} \\
\hline Normal & 52 & 52 & 44 & 44 & & \\
\hline Hyperglycemia & 48 & 48 & 52 & 52 & & \\
\hline \multicolumn{7}{|l|}{ RBS 2} \\
\hline Hypoglycemia & 4 & 4 & 12 & 12 & \multirow{3}{*}{2.272} & \multirow{3}{*}{0.322} \\
\hline Normal & 36 & 36 & 20 & 20 & & \\
\hline Hyperglycemia & 60 & 60 & 68 & 68 & & \\
\hline \multicolumn{7}{|l|}{ RBS 3} \\
\hline Hypoglycemia & 16 & 16 & 12 & 12 & \multirow{3}{*}{5.112} & \multirow{3}{*}{0.078} \\
\hline Normal & 72 & 72 & 48 & 48 & & \\
\hline Hyperglycemia & 12 & 12 & 40 & 40 & & \\
\hline \multicolumn{7}{|l|}{ RBS 4} \\
\hline Hypoglycemia & 8 & 8 & 24 & 24 & \multirow{3}{*}{8.173} & \multirow{3}{*}{$0.017^{\star}$} \\
\hline Normal & 68 & 68 & 28 & 28 & & \\
\hline Hyperglycemia & 24 & 24 & 48 & 48 & & \\
\hline \multicolumn{7}{|l|}{ RBS 5} \\
\hline Hypoglycemia & 0 & 0 & 12 & 12 & \multirow{3}{*}{7.862} & \multirow{3}{*}{$0.019^{*}$} \\
\hline Normal & 80 & 80 & 44 & 44 & & \\
\hline Hyperglycemia & 20 & 20 & 44 & 44 & & \\
\hline \multicolumn{7}{|l|}{ RBS 6} \\
\hline Hypoglycemia & 0 & 0 & 4 & 4 & \multirow{3}{*}{13.764} & \multirow{3}{*}{$0.001^{*}$} \\
\hline Normal & 76 & 76 & 24 & 24 & & \\
\hline Hyperglycemia & 24 & 24 & 72 & 72 & & \\
\hline \multicolumn{7}{|l|}{ RBS 7} \\
\hline Hypoglycemia & 0 & 0 & 8 & 8 & \multirow{3}{*}{6.103} & \multirow{3}{*}{$0.047^{*}$} \\
\hline Normal & 68 & 68 & 36 & 36 & & \\
\hline Hyperglycemia & 32 & 32 & 56 & 56 & & \\
\hline \multicolumn{7}{|l|}{ RBS 8} \\
\hline Hypoglycemia & 0 & 0 & 4 & 4 & \multirow{3}{*}{7.631} & \multirow{3}{*}{$0.013^{*}$} \\
\hline Normal & 52 & 52 & 16 & 16 & & \\
\hline Hyperglycemia & 48 & 48 & 80 & 80 & & \\
\hline
\end{tabular}

Table 4: Comparison between the two studied group according to RBS.

in the number of deaths in the patient group after amino acids infusion if compared to the control group (Tables 6 and 7).

\section{Discussion}

Neonatal hyperglycemia is a common problem in preterm or sick neonates in the first few weeks of life. Increased frequency associated with lower gestational age and birth weight as well as severe clinical conditions $[4,5]$.
There is currently no best practice method or target for glycemic control in preterm babies and blood glucose is often controlled by varying nutritional input, which may restrict infant growth and cause adverse neurodevelopmental outcomes [11-13].

Early postnatal provision of IV amino acids to preterm infants produces greater rates of protein synthesis and net protein balance [10].

This study was designed to evaluate the value of IV AAs infusion on the reduction of neonatal hyperglycemia and their effect on protein synthesis especially albumin.

In this study, there was significant decrease in the number of hyperglycemic and hypoglycemic patient with improvement of glycemic variability starting from the fourth day of life after the amino acids infusion which was in agreement with Auerbach et al. and our study was also in agreement with Marcelo and Nestor, who stated that Long duration of hyperglycemia in the first 96 hours of life is associated with severe intraventricular hemorrhage in preterm infants and therefore revealed the importance of early AA infusion to decrease the number of hyperglycemic and hypoglycemic patient with improvement of glycemic variability $[3,4]$.

In our study neonates who received AAs had a significantly reduced incidence of hyperglycemia and this was in agreement with Burattini et al. [10].

In this study, there was statistically significant increase of the TSP level after amino acid infusion in the patient group and there was also significant increase in the TSP level in the 2 nd reading of the patient

\begin{tabular}{|c|c|c|c|c|}
\hline TSP (gm/dl) & Cases $(n=25)$ & Control $(n=25)$ & $\mathbf{t}$ & $\mathbf{P}$ \\
\hline \multicolumn{5}{|l|}{$1 \mathrm{st}$} \\
\hline Range & $3.30-8.80$ & $4.60-6.80$ & \multirow{2}{*}{1.69} & \multirow{2}{*}{0.101} \\
\hline Mean \pm SD. & $5.47 \pm 1.37$ & $5.97 \pm 0.55$ & & \\
\hline \multicolumn{5}{|l|}{ 2nd } \\
\hline Range & $4.90-7.90$ & $3.30-7.10$ & \multirow{2}{*}{3.995} & \multirow{2}{*}{$0.010^{*}$} \\
\hline Mean \pm SD. & $6.30 \pm 0.81$ & $5.63 \pm 0.92$ & & \\
\hline \multicolumn{5}{|c|}{ t: Student t-test ${ }^{*}$ Statistically significant at $p \leq 0.05$. } \\
\hline
\end{tabular}

Table 5: Comparison between the two studied groups as regard to TSP.

\begin{tabular}{|c|c|c|c|c|}
\hline Albumin & Cases $(n=25)$ & Control $(n=25)$ & $\mathbf{t}$ & $\mathbf{P}$ \\
\hline \multicolumn{5}{|l|}{ 1st } \\
\hline Range & $1.90-4.80$ & $2.30-4.60$ & \multirow{2}{*}{1.204} & \multirow{2}{*}{0.236} \\
\hline Mean \pm SD. & $3.02 \pm 0.75$ & $3.23 \pm 0.46$ & & \\
\hline \multicolumn{5}{|l|}{ 2nd } \\
\hline Range & $2.80-4.60$ & $2.0-3.40$ & \multirow{2}{*}{$5.125^{*}$} & \multirow{2}{*}{$<0.001$} \\
\hline Mean \pm SD & $3.48 \pm 0.40$ & $2.91 \pm 0.38$ & & \\
\hline
\end{tabular}

Table 6: Comparison between the two studied groups according to serum albumin.

\begin{tabular}{|c|c|c|c|c|c|}
\hline \multicolumn{3}{|c|}{ Outcome } & Patients & Control & Total \\
\hline \multirow[t]{2}{*}{ Alive } & & $N$ & 22 & 15 & 38 \\
\hline & & $\%$ & $88.00 \%$ & $60.00 \%$ & $76.00 \%$ \\
\hline \multirow[t]{2}{*}{ Dead } & & $\mathrm{N}$ & 3 & 10 & 12 \\
\hline & & $\%$ & $12.00 \%$ & $40.00 \%$ & $24.00 \%$ \\
\hline \multirow[t]{2}{*}{ Total } & & $N$ & 25 & 25 & 50 \\
\hline & & $\%$ & $100.00 \%$ & $100.00 \%$ & $100.00 \%$ \\
\hline \multirow[t]{2}{*}{ Chi-square } & $\mathrm{X} 2$ & \multicolumn{4}{|c|}{5.092} \\
\hline & P-value & \multicolumn{4}{|c|}{$0.024^{*}$} \\
\hline
\end{tabular}

Table 7: Comparison between the two studied groups as regard the outcome. 
group if compared with the same reading of the control group that did not receive amino acid infusion.

In our study, there was significant increase in the albumin level in the patient group after amino acid infusion and there was also significant increase in the same level if compared to the albumin level of the control group on the 8th day of life.

This is in agreement with Trivedi and Sinn, who studied early versus late administration of amino acids in preterm infants receiving parenteral nutrition and found that AAs infusion in the first days of life increases albumin synthesis rates in premature neonates. Albumin synthesis rate and plasma albumin concentrations were significantly higher in premature infants who had received parenteral AAs than in those who had not received parenteral AAs with better outcome and prognosis [12].

Providing AAs after birth increases albumin synthesis and this higher albumin synthesis rate makes premature infants less vulnerable to catabolic insults through the temporary storage of AAs in albumin, which prevents excess AAs from being oxidized [14].

In our study there was significant decrease in the albumin level on the 8th day if compared with the same level on the 3rd day of life in the control group and this can be explained by the renal loss of AAs, which is needed for stimulation of protein synthesis, that occur physiologically in neonates as the tubular reabsorption of AAs is lower in neonates than in older children, such that the normal neonate has relative generalized amino acidurea $[11,14]$.

\section{Conclusions}

Amino acids infusion in preterm neonates lead to improvement of glycemic variability including hyperglycemia and hypoglycemia and also cause stimulation of protein synthesis in the form of total serum proteins and albumin with improvement of their outcome reducing the mortality.

\section{Acknowledgement}

The authors acknowledge Mrwa Abd Elwahab, Neama Soliman, who contributed towards the study by making substantial contributions to conception, design, analysis and interpretation of data.

\section{References}

1. Goldenberg RL, Gravett MG, lams J, Papageorghiou AT, Waller SA, et al. (2012) The preterm birth syndrome: issues to consider in creating a classification system. Am J Obstet Gynecol 206: 113-118.
2. Alsweiler JM, Harding JE, Bloomfield FH (2012) Tight glycemic control with insulin in hyperglycemic preterm babies: a randomized controlled trial. Pediatrics 129: 639-647.

3. Auerbach A, Eventov-Friedman S, Arad I, Peleg O, Bdolah-Abram T, et al. (2013) Long duration of hyperglycemia in the first 96 hours of life is associated with severe intraventricular hemorrhage in preterm infants. J Pediatr 163: 388393.

4. Decaro MH, Vain NE (2011) Hyperglycaemia in preterm neonates: what to know, what to do. Early Hum Dev 87 Suppl 1: S19-22.

5. Chase JG, Le Compte AJ, Suhaimi F, Shaw GM, Lynn A, et al. (2011) Tight glycemic control in critical care - The leading role of insulin sensitivity and patient variability: A review and model-based analysis. Computer Methods and Programs in Biomedicine 10: 156-171.

6. Doyle LW, Ehrenkranz RA, Halliday HL (2014) Early (< 8 days) postnatal corticosteroids for preventing chronic lung disease in preterm infants. Cochrane Database Syst Rev 5: CD001146.

7. Kalhan SC, Devaskar SU (2011) Disorders of carbohydrate metabolism. (9th edn), Elsevier, USA.

8. Blanco CL, Gong AK, Green BK, Flack A, Schoolfield J, et al. (2011) Early changes in plasma amino acid concentrations during aggressive nutritional therapy in extremely low birth weight infants. J Pediatr 4: 158:543.

9. Bremer AA, Mietus-Snyder M, Lustig RH (2012) Toward a unifying hypothesis of metabolic syndrome. Pediatrics 129: 557-570.

10. Burattini I, Bellagamba MP, Spagnoli C, D'Ascenzo R, Mazzoni N, et al. (2013) Targeting 2.5 versus $4 \mathrm{~g} / \mathrm{kg} /$ day of amino acids for extremely low birth weight infants: a randomized clinical trial. J Pediatr 163: 1278-1282.

11. Rayvan M, Devliger $H$, Jochum $F$ (2012) Short-term use of parenteral nutrition with a lipid emulsion containing a mixture of soybean oil, olive oil, mediumchain triglycerides and fish oil: A randomized double-blind study in preterm infants. J Parenter Enteral Nutr 36: 81S-94S.

12. Trivedi A, Sinn JK (2013) Early versus late administration of amino acids in preterm infants receiving parenteral nutrition. Cochrane Database Syst Rev 7: CD008771.

13. Tsubahara M, Shoji $H$, Mori M, Matsunaga N, Ikeno M, et al. (2012) Glucose metabolism soon after birth in very premature infants with small- and appropriate-for-gestational-age birth weights. Early Hum Dev 88: 735-738.

14. Vlaardingerbroek $\mathrm{H}$, Vermeulen MJ, Rook D, van den Akker $\mathrm{CH}$, Dorst $\mathrm{K}$, et al. (2013) Safety and efficacy of early parenteral lipid and high-dose amino acid administration to very low birth weight infants. J Pediatr 163:638. 